\title{
ANÁLISE DE FORMAS E FEIÇÕES GEOMORFOLÓGICAS DESENVOLVIDAS EM ARENITOS NAS BACIAS HIDROGRÁFICAS DO RIO NOVO (TOCANTINS) E DO RIO IBICUÍ (RIO GRANDE DO SUL)
}

\author{
Sandro Sidnei Vargas de Cristo \\ Universidade Federal do Tocantins, Curso de Graduação e Pós-graduação em Geografia \\ Porto Nacional, TO, Brasil \\ sidneicristo@uft.edu.br \\ Luis Eduardo de Souza Robaina \\ Universidade Federal de Santa Maria, Cursos de Graduação e Pós-Graduação em Geografia \\ Santa Maria, RS, Brasil \\ lesrobaina@yahoo.com.bm
}

\begin{abstract}
RESUMO
A pesquisa apresenta as formas e feições geomorfológicas encontradas nas bacias hidrográficas do rio Ibicuí, localizada no estado do Rio Grande do Sul e do rio Novo, localizada no estado do Tocantins, analisando as semelhanças entre processos atuantes e as respostas das rochas areníticas. Os procedimentos metodológicos tiveram como base a identificação, localização e descrição das formas e feições, utilizando-se observações cartográficas apoiadas por diversos trabalhos de campo. Os fatores responsáveis pela evolução das feições erosivas dos arenitos estão relacionados as características das rochas, como textura, estrutura sedimentar, cimentação, falhas e fraturas. Estas características determinam processos de intemperismo e erosão diferenciados na rocha arenítica proporcionando a geração de uma ampla geodiversidade de formas e feições, representada pela presença de relevos regionais residuais de topos planos e ruiniformes; formas locais representadas por furnas, cavernas, pináculos, torres, blocos e matacões com cobertura imbricada, além de erosão e deposição como voçorocas, areais e dunas.
\end{abstract}

Palavras-chave: Formas e Feições de Relevo. Rochas Areníticas. Geodiversidade. Geomorfologia.

\section{ANALYSIS FORMS AND FEATURE GEOMORPHOLOGICAL DEVELOPED IN SANDSTONES IN THE HYDROGRAPHIC BASIN OF THE NOVO RIVER (TOCANTINS) AND IBICUI RIVER (RIO GRANDE DO SUL)}

\begin{abstract}
The research presents the forms and geomorphological features found in the lbicuí river basins, located in the state of Rio Grande do Sul and the Novo River, located in the state of Tocantins, analyzing the similarities between active processes and the responses of sandstone rocks. The methodological procedures were based on the identification, location and description of the forms and features, using cartographic observations supported by several field works. In general, it is observed that the factors responsible for the evolution of the erosive features of the sandstones in both areas are related to rocks characteristics, such as: texture, sedimentary structure, cementation, fractures and faults. These characteristics determine processes of weathering and erosion differentiated in the sandstone which generates a wide geodiversity of forms and features, represented by the presence of residual reliefs of flat and ruiniform tops, local feature as such as furnas, caves, pinnacles, towers, blocks and boulders with imbricated cover, besides erosion and deposition like gullies, sand and dunes.
\end{abstract}

Keywords: Forms and Features of Relief. Sandstones. Geodiversity. Geomorphology 


\section{INTRODUÇÃO}

O estudo das formas de relevo se apresenta como objeto de estudo da Geomorfologia, tanto nos aspectos de gênese como evolução destas formas. Para Guerra (1993) Geomorfologia é a ciência que estuda as formas de relevo, tendo em vista a origem, estrutura, natureza das rochas, o clima da região e as diferentes forças endógenas e exógenas que, de modo geral, entram como fatores que influenciam o relevo terrestre. As unidades do relevo que guardam as informações paleo-ambientais permitem entender os fatores de controle desencadeadores de processos esculturadores.

Conforme Ab'Saber (1977) a topografia ruiniforme são heranças de processos geológicos e geomorfológicos, mais ou menos complexos, que se enquadram na categoria das paisagens de exceção.

Para Meira e Santos (2016) em estudos na Serra dos Tapuios, oeste da Bahia, o relevo ruiniforme é oriundo da erosão diferencial em arenito com discordância textural.

Hardt e Pinto (2009) e Melo et al. (2011) destacam o potencial de desenvolvimento de formas de relevo cárstico em quartzitos e arenitos como ocorre na Chapada Diamantina, estado da Bahia; do plato quartzítico do noroeste da Amazônia e na região da Serra da Capivara e Sete Cidades no Piauí, onde está a maior caverna em arenito do Brasil, a Toca das Confusões, com 1633m (Rodet, citado por Chabert e Courbon, 1997).

A diversidade de feições encontradas por Melo et al. (2011) demonstra que, além de existir um sistema cárstico desenvolvido em rochas não-carbonáticas, os arenitos são importantes na formação das diferentes formas do relevo e nos processos da dinâmica natural que integram a paisagem.

Robaina e Bazzan (2008) destacam a região oeste-sudoeste do estado do Rio Grande do Sul, onde ocorrem formas ou associação de formas em terrenos areníticos, semelhantes as formas de relevo cárstico. Estes estudaram a Gruta Nossa Senhora de Fátima, localizada em Nova Esperança do Sul, que se desenvolve junto as vertentes encaixadas do rio Jaguarí em substrato de arenitos fluviais.

A descrição de relevo semelhante ao cárstico do calcário, mas desenvolvido em rochas siliciclásticas, já vinha sendo reportada na literatura desde a década de 1950 (Renault, 1953). Entretanto, White et al. (1996) foram os primeiros autores a realizarem trabalhos mais sistemáticos sobre carstificação, nesse tipo de litologia, abrindo um novo campo para as investigações geomorfológicas.

Referindo-se aos aspectos geomorfológicos da bacia hidrográfica do rio Itu, região oeste do Rio Grande do Sul, Trentin et al. (2012) identificaram diversas formas em rochas areníticas, das quais destacam-se a presença dos areais, ravinas e voçorocas, cornijas e morrotes de topos planos, conhecidas regionalmente como cerros.

Morais e Rocha (2011) analisam as cavidades do Planalto Residual do Tocantins desenvolvidas em arenitos, que podem resultar de vários processos, tais como: intemperismo químico, erosão (corrasão), fragmentação da rocha e movimentos gravitacionais de massa.

Segundo Cristo e Robaina (2016) percebe-se uma diversidade de formas e processos em rochas areníticas, na porção leste do estado do Tocantins, região do Jalapão, dando origem a formação de dunas eólicas, morros e morrotes, representados por relevos residuais com topos arredondados; as mesas e mesetas, caracterizadas como relevos residuais tabulares descontínuos e as chapadas, que são relevos tabulares, topos planos e retilíneos, com grande continuidade de área.

As pesquisas realizadas na região oeste do Rio Grande do Sul, na bacia hidrográfica do rio lbicuí e na porção leste de Tocantins, na bacia hidrográfica do rio Novo, indicaram a existência de formas de relevo semelhantes associados às respostas das rochas areníticas a processos de intemperismo e erosão, desenvolvendo um relevo muito característico.

O estudo se justifica pela pouca ocorrência de trabalhos com descrição e análise das variadas feições e formas de relevo nas áreas das bacias hidrográficas em questão. Além disso, essas bacias ocorrem em ambientes com grande suscetibilidade erosiva, com a presença de uso agrícola e paisagens que precisam ser conservadas.

A bacia hidrográfica do rio Ibicuí faz parte do Bioma Pampa e se associa a sequencias de rochas sedimentares de composição arenítica da Bacia do Paraná, de idade Mesozóica, que compõem a unidade geomorfológica Depressão Periférica do Rio Grande do Sul, subunidade Depressão do Ibicuí (Robaina et al. 2010). A bacia hidrográfica do rio Novo faz parte da região do Jalapão, constituída geologicamente pela bacia sedimentar Sanfranciscana, onde predominam rochas do Grupo Urucuia,

$\begin{array}{llllll}\text { Caminhos de Geografia } & \text { Uberlândia - MG } & \text { v. 19, n. } 67 & \text { Set/2018 } & \text { p. 143-156 Página } 144\end{array}$


do Neocretáceo (Gaspar, 2006), recoberta por depósitos sedimentares recentes. Ressalta-se que a mesma faz parte da Estação Ecológica Serra Geral do Tocantins composta pelo Bioma Cerrado.

Deste modo, a presente pesquisa, tem como principal objetivo realizar uma análise das formas e feições de relevos desenvolvidas em rochas areníticas do oeste do estado do Rio Grande do Sul e do leste do estado do Tocantins, tomando-se como base estudos das bacias hidrográficas com importâncias regionais, do rio Ibicuí (Figura 1), representando o oeste do Rio Grande do Sul, e o alto curso da bacia hidrográfica do rio Novo, o leste do Tocantins (Figura 2).

Figura 1: Bacia hidrográfica do Rio Ibicuí - Rio Grande do Sul.

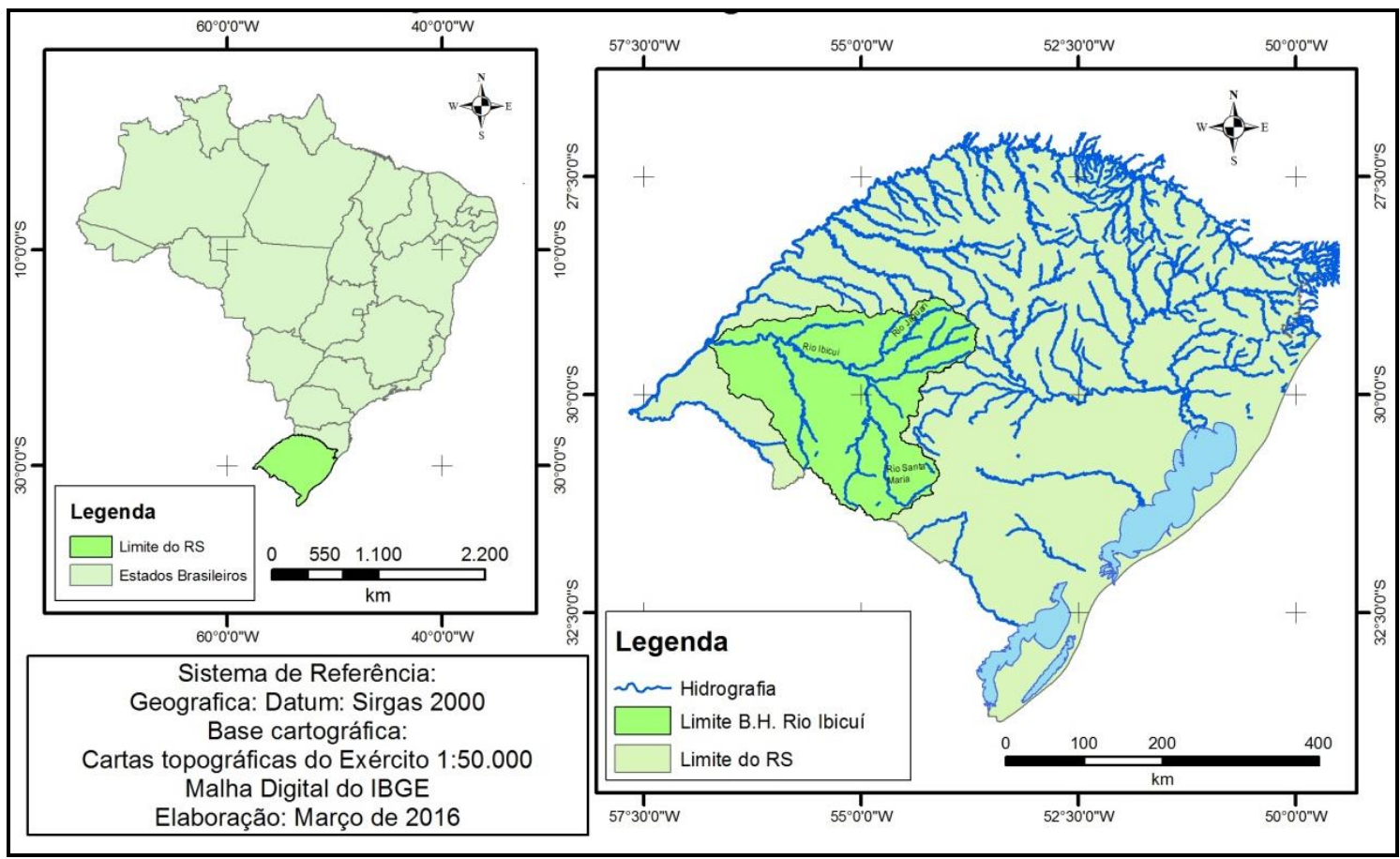

Edição: Trentin (2016)

O trabalho busca contribuir com a discussão sobre o relevo marcado por feições como elevações de topos aplainados, formas ruiniformes desenvolvidas por blocos desagregados, torres e pináculos, além de cavernas devido à ação erosiva mecânica e dissolução de cimentos.

Ainda, analisa-se a resposta aos processos superficiais de intemperismo e erosão que estão associados às características das rochas como a presença de matriz e a estrutura sedimentar e tectônica desenvolvida.

A bacia hidrográfica do Rio Ibicuí ocupa uma área de aproximadamente $46.602,58 \mathrm{~km}^{2}$, está localizada na porção oeste do estado do Rio Grande do Sul, entre as coordenadas $29^{\circ} 01^{\prime}$ e e $31^{\circ} 20^{\prime}$ de latitude sul e entre as coordenadas $56^{\circ} 47^{\prime}$ e $53^{\circ} 29^{\prime}$ de longitude oeste. $O$ alto curso da bacia hidrográfica do Rio Novo possui uma área com cerca de $5.168,5 \mathrm{~km}^{2}$, tem suas nascentes na Serra Geral, abrangendo os municípios de Mateiros, localizado no estado do Tocantins e Formosa do Rio

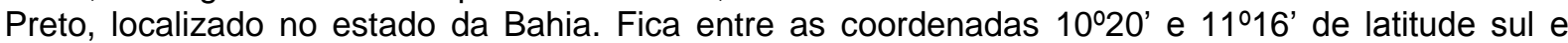
entre as coordenadas $47^{\circ} 06^{\prime}$ e $45^{\circ} 56^{\prime}$ de longitude oeste. 
Figura 2: Alto curso da bacia hidrográfica do Rio Novo.

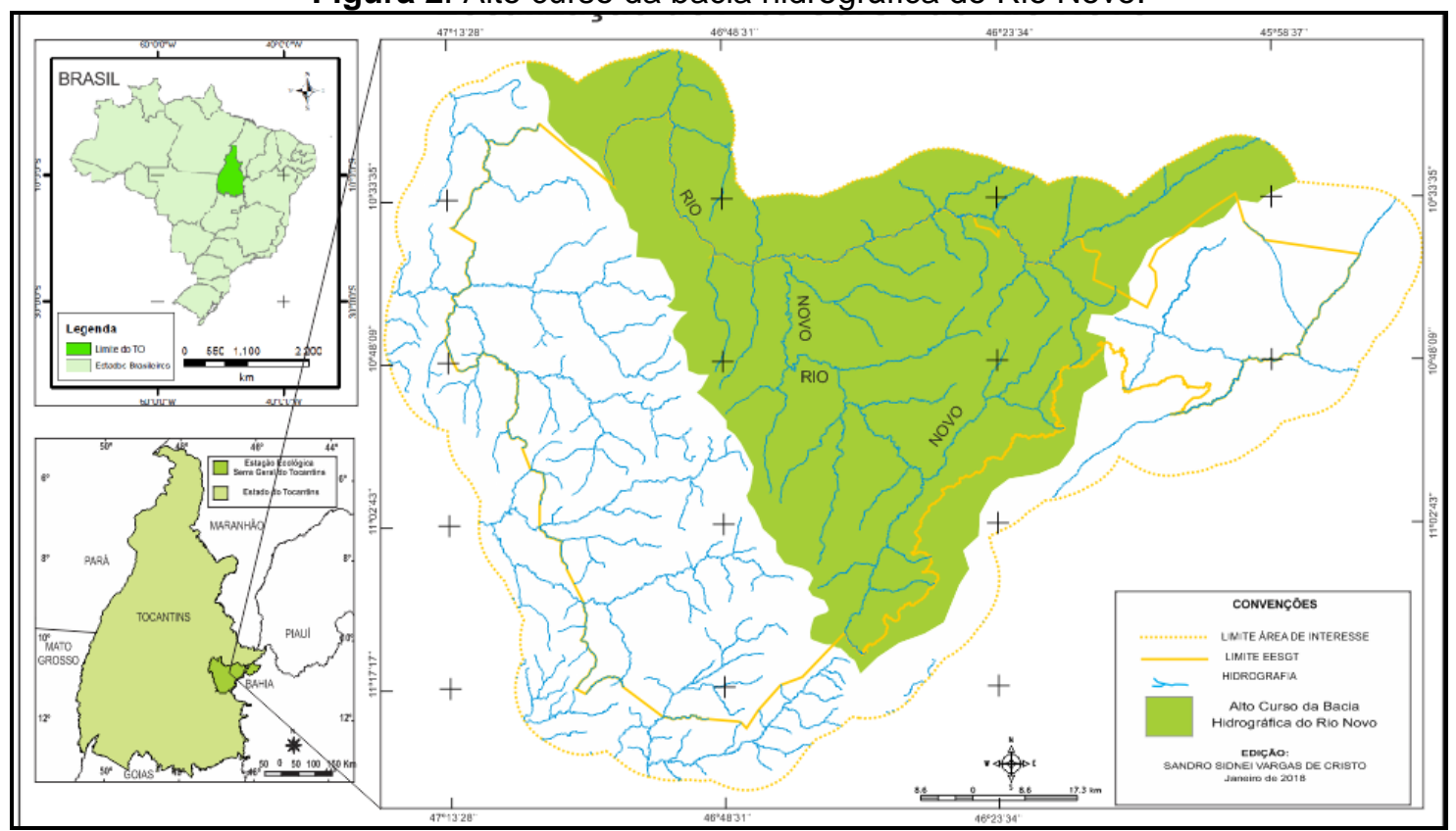

Edição: Cristo (2018)

\section{PROCEDIMENTOS TÉCNICOS E METODOLÓGICOS}

Nos procedimentos fez-se o uso do geoprocessamento com a organização de um banco de dados via Sistema de Informação Geográfica (SIG) utilizando o software Sistema de Processamento de Informações Georreferenciadas (SPRING) do Instituto Nacional de Pesquisas Especiais (INPE) e o software Arcgis 10 da ESRI.

Utilizou-se imagens de satélites (Landsat) e de radar Shuttle Radar Topography Mission (SRTM), além de cartas topográficas da Diretoria do Serviço Geográfico do Exército (DSG) e do Instituto Brasileiro de Geografia e Estatística (IBGE), mapas e arquivos digitais.

Os trabalhos cartográficos relativos ao alto curso da bacia hidrográfica do rio Novo foram realizados no Laboratório de Geoprocessamento (LABGEOP) do Curso de Geografia (Campus de Porto Nacional), na Universidade Federal do Tocantins (UFT) e, os trabalhos relativos à bacia hidrográfica do rio lbicuí, foram realizados no Laboratório de Geologia Ambiental (LAGEOLAM), na Universidade Federal de Santa Maria (UFSM).

Para identificação, localização e descrição das formas e feições geomorfológicas, foram feitas observações cartográficas apoiadas por diversos trabalhos de campo realizados através de perfis feitos por caminhos e estradas das áreas em pesquisa, com uso de receptor de Sistema de Posicionamento Global (GPS) e máquina fotográfica digital.

No alto curso da bacia hidrográfica do Rio Novo, os trabalhos de campo tiveram apoio do Instituto Chico Mendes da Conservação da Biodiversidade (ICMBio) - Estação Ecológica Serra Geral do Tocantins e, na bacia hidrográfica do rio lbicuí, tiveram apoio do Laboratório de Geologia Ambiental (LAGEOLAM) da Universidade Federal de Santa Maria (UFSM).

\section{FORMAS E FEIÇÕES GEOMORFOLÓGICAS}

De modo geral, os aspectos geológicos-geomorfológicos em ambas as bacias hidrográficas, do rio Novo e do rio lbicuí, estão relacionados aos depósitos sedimentares e rochas areníticas com ação de processos de intemperismo e de erosão diferenciados dependendo das caraterísticas texturais e estruturais das litologias.

Os fatores condicionantes no desenvolvimento e evolução das feições e formas nos arenitos são de múltipla natureza, relacionados a atributos das rochas sedimentares, como textura, estrutura sedimentar, cimentação e/ou relacionados a estruturas rúpteis como falhas e fraturas.

$\begin{array}{llllll}\text { Caminhos de Geografia } & \text { Uberlândia - MG } & \text { v. 19, n. } 67 & \text { Set/2018 } & \text { p. 143-156 Página } 146\end{array}$


Com relação aos fatores intrínsecos, os aspectos texturais controlam a possibilidade e percolação de fluidos na rocha, interferindo nos processos de cimentação e neoformação, durante a diagênese, e após sua exposição na superfície os processos de intemperismo e erosão.

Os processos diagenéticos que afetam o sedimento durante a litificação são determinantes no comportamento dos arenitos frente aos processos intempéricos e erosivos. A ocorrência de cimentação influência nas mudanças da porosidade das rochas e no grau de aglutinação das partículas. $O$ tipo de cimento presente e, como este cimento está distribuído nos poros das rochas, influenciam na percolação das águas e, portanto, nos processos atuantes.

Os cimentos silicosos caracterizam uma maior resistência aos processos superficiais, pela maior estabilidade da sílica, enquanto, cimentos de óxido de ferro, argila e carbonato podem ser mobilizados por mudanças nas condições de oxidação e acidificação.

Além disso, a cimentação pode ser ora como película envolvendo os grãos, ora ocupando totalmente o espaço entre os grãos e é, em parte, o motivo da variação de resistência das diferentes camadas dos arenitos aos processos erosivos (erosão diferencial).

Melo et al. (2011) analisando a petrografia dos arenitos, indica que o cimento argiloso relativamente solúvel envolvendo grãos de quartzo menos solúveis, é um importante fator controlador dos processos erosivos nos arenitos da Formação Furnas.

Nas áreas de estudo os arenitos apresentam cimentação irregular formando camadas com diferentes resistências. Quando o óxido de ferro preenche os poros confere coesão à rocha e resistência aos processos erosivos. A Figura 3 apresenta fotomicrografias da rocha arenítica observada na gruta desenvolvida na bacia hidrográfica do rio lbicuí, onde se observa os diferentes níveis de cimentação. $\mathrm{Na}$ Figura 3A ocorre uma maior aglutinação dos grãos pelo cimento de óxido de ferro, em relação à imagem da Figura 3B.

Figura 3: Fotomicrografias de arenitos, mostrando a variação relativa de cimentação.

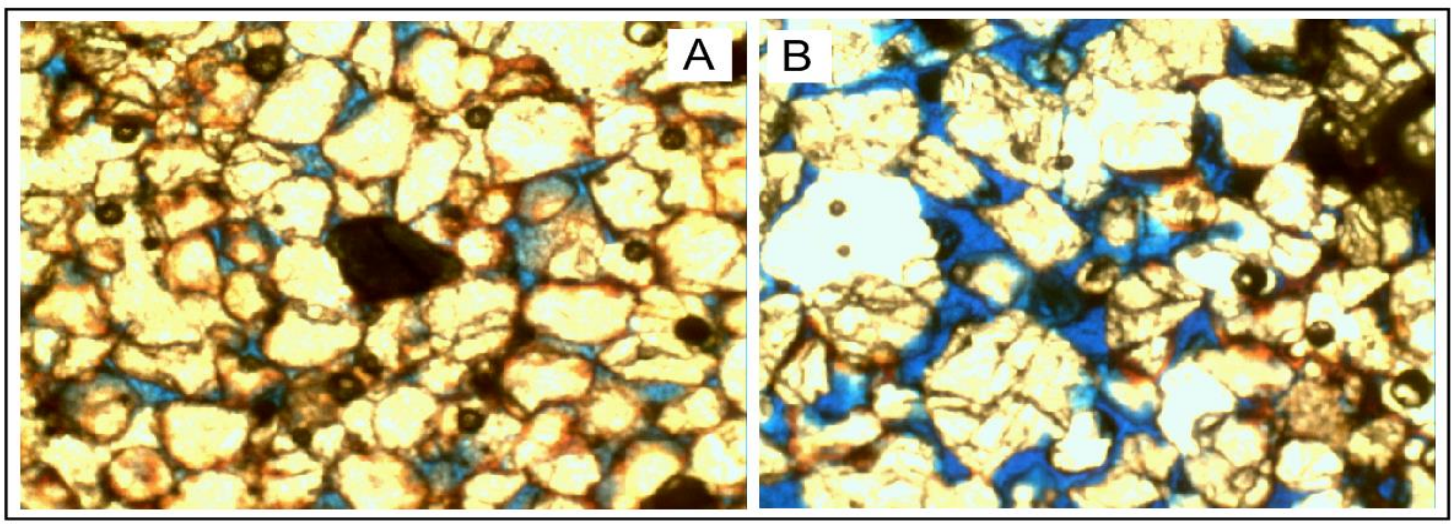

Fonte: Autores, (A e B 2014)

Ainda na Figura 3A pode-se observar que o cimento de óxido preenche a ligação entre os grãos e na Figura 3B os poros estão com baixa cimentação.

As estruturas sedimentares e rúpteis controlam a possibilidade de percolação da água através da rocha, desenvolvendo planos e dutos de fluxo concentrado. No processo de erosão subterrânea, em rochas areníticas, a geometria interna dos planos de estratificação e fraturas controlam o desenvolvimento dos dutos (ROBAINA e BAZZAN, 2008).

Conforme Melo et al. (2011) nas rochas areníticas as estruturas rúpteis (falhas e fraturas) que se associam ao embasamento ou à deriva, têm nas direções estruturais, o papel fundamental na circulação da água subterrânea e evolução das formas erosivas das rochas dos Campos Gerais.

Estudos desenvolvidos em grutas siliciclásticas têm enfatizado a importância da presença de constituintes mais facilmente intemperizáveis da rocha, de maneira a possibilitar desenvolvimento inicial de rotas de fluxo subterrâneo. Além disso, há um consenso entre vários autores a respeito do notável controle que as estruturas geológicas exercem no desenvolvimento das paisagens em arenitos.

$\begin{array}{llllll}\text { Caminhos de Geografia } & \text { Uberlândia - MG } & \text { v. 19, n. } 67 & \text { Set/2018 } & \text { p. 143-156 } & \text { Página } 147\end{array}$


A estratificação, nas rochas areníticas estudadas, se caracteriza por estratos longos e a ocorrência de estruturas frágeis, que podem ser observadas nas fotografias da Figura 4 que representam zonas de descontinuidades e, portanto, mais frágeis à erosão interna. A estrutura geológica se apresenta como guia inicial na direção do fluxo da água, influenciando diretamente no trabalho de erosão e dissolução em subsuperfície.

Figura 4: Estratificação e fraturas existentes no arenito Guará (A e B) que formam importantes feições e formas na Bacia hidrográfica do rio lbicuí.

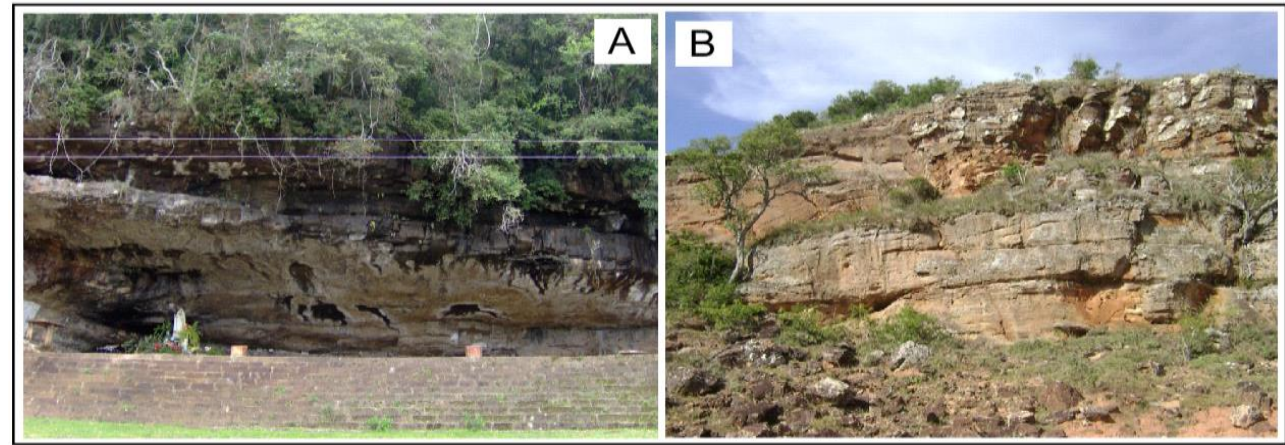

Fonte: Autores, (A e B 2016)

Localização: (A) Latitude Sul $29^{\circ} 49^{\prime}$ e Longitude Oeste $54^{\circ} 67^{\prime}$ (B) Latitude Sul $29^{\circ} 39^{\prime}$ e Longitude Oeste $54^{0} 79^{\prime}$

Nas áreas de estudo, podem ser observadas diversas formas e feições desenvolvidas em arenitos que demonstram a expressiva geodiversidade das mesmas, representada por formas regionais como morrotes e morros residuais de topos planos e ruiniformes; feições locais de furnas ou cavernas, pináculos, feições ruiniformes, blocos areníticos de cobertura imbricada; feições erosivas e deposição de areias representadas por voçorocas, areais e dunas.

\section{FORMAS E FEIÇÕES REGIONAIS}

As Feições de Relevos Residuais com Topos Planos se caracterizam pelos relevos residuais de morros e morrotes com topos planos e encostas escarpadas, decorrentes da erosão regressiva ou recuo das escarpas.

As características destas feições podem ser observadas na Serra da Muriçoca, Serra Geral, Serra do Espírito Santo (Figuras 5A e 5B) e no morro da Bigorna, no alto curso da bacia hidrográfica do rio Novo e na bacia hidrográfica do rio lbicuí, onde aparecem formando o primeiro patamar do rebordo (Figura 6A) e nos morros e morrotes de topos planos (Figura 6B).

Figura 5: Relevos residuais de topos planos da Serra do Espírito Santo (A e B) no alto curso da bacia hidrográfica do rio Novo.

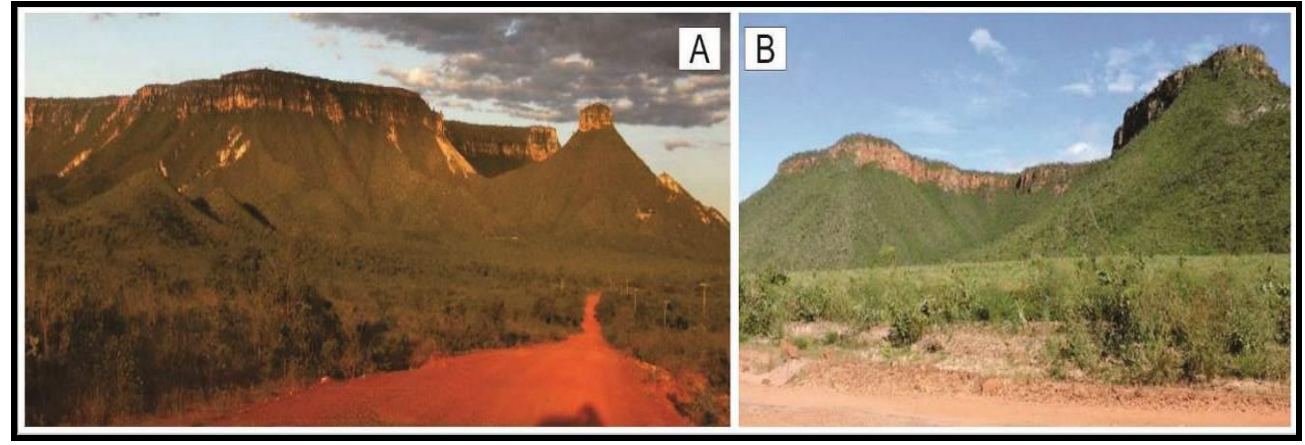

Fonte: Autores, (A 2012) e (B 2014)

Localização: Latitude Sul $10^{\circ} 31^{\prime}$ e Longitude Oeste $46^{\circ}$ e $34^{\prime}$ 
Figura 6: Relevos residuais de topos planos na bacia hidrográfica do rio lbicuí (A e B).

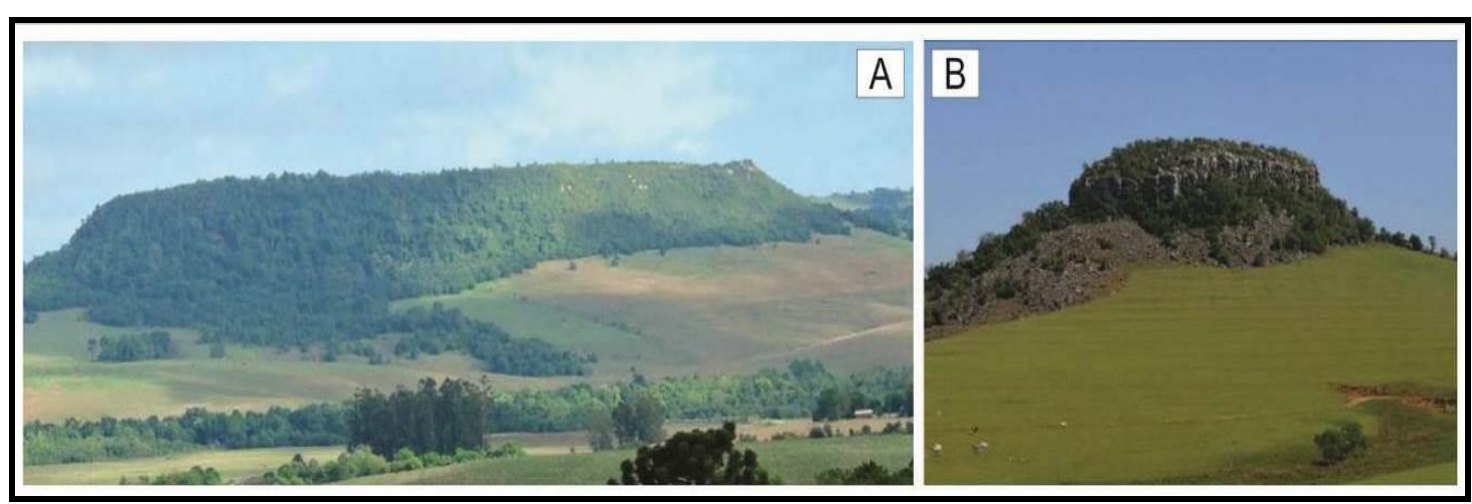

Fonte: Autores, (A 2014) e (B 2012)

Localização: Latitude Sul $29^{\circ} 42^{\prime}$ e Longitude Oeste $54^{0} 53^{\prime}$

Estas feições são formadas por rochas sedimentares estratificadas, topos planos e encostas escarpadas, características de relevos tabulares mantidos por camadas resistentes.

Destaca-se, na bacia hidrográfica do rio Novo, o Morro da Bigorna (Figura 7A) que por sua forma alongada e topo plano, lembra uma "Bigorna", instrumento de trabalho muito utilizado antigamente pelos ferreiros na fabricação de ferramentas de metal, ferraduras de cavalos, entre outras.

No mesmo sentido, o Cerro do Loreto (Figura 7B) é um exemplo, na bacia hidrográfica do rio Ibicuí, como um dos morrotes isolados de topos planos, que marcam o recuo do Rebordo do Planalto na porção norte da bacia.

Figura 7: Morro da Bigorna (A) e o Cerro do Loreto (B).

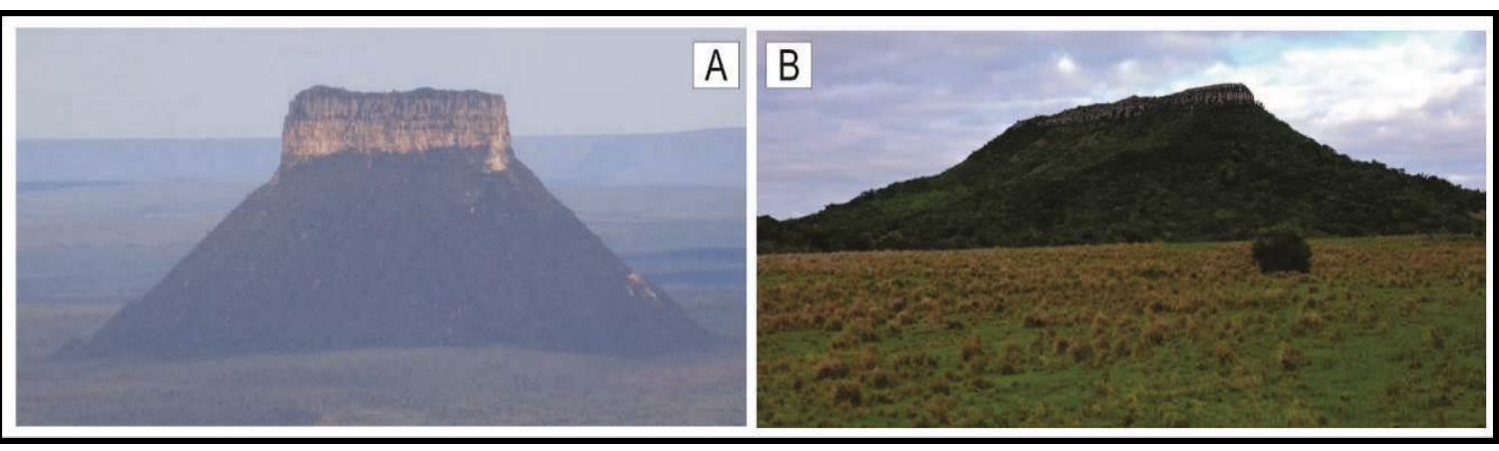

Fonte: Autores, (A 2011) e (B 2016)

Localização: (A) Latitude Sul $10^{\circ} 52^{\prime}$ e Longitude Oeste $46^{\circ} 41^{\prime}$ (B) Latitude Sul $29^{\circ} 42^{\prime}$ e Longitude Oeste $54^{0} 53^{\prime}$

Os Relevos Residuais com Topos Ruiniformes se caracterizam por morros e morrotes, com encostas escarpadas e topos constituídos por blocos, pináculos e torres. Essas formas areníticas com aspecto de ruínas, na parte superior das feições, se originam pelas características da estratificação, fraturamento e fragilidade rochosa frente aos processos erosivos que atuam verticalmente nas rochas sedimentares.

Estas feições podem ser observadas, no alto curso da bacia hidrográfica do rio Novo, associado ao Morro do Fumo (Figura 8A), o qual se caracteriza por possuir suas encostas escarpadas recobertas por um significativo depósito de talús e colúvios e, uma cobertura constituída por exposição de arenitos em forma de ruinas. Formas estas que demonstram a fragilidade geológica das formas e feições da região.

$\begin{array}{llllll}\text { Caminhos de Geografia } & \text { Uberlândia - MG } & \text { v. 19, n. } 67 & \text { Set/2018 } & \text { p. 143-156 } & \text { Página } 149\end{array}$


Na bacia hidrográfica do rio Ibicuí, são representadas pelo Cerro do Tigre (Figura 8B) localizado na sua margem esquerda. Neste, observa-se uma encosta formada por um depósito de diversos blocos irregulares e a ação da erosão diferencial gerando uma "ponte de pedra" em seu topo.

Figura 8: Relevos Residuais com Topos Ruiniformes da bacia hidrográfica do rio Novo, Morro do Fumo (A) e da bacia hidrográfica do rio Ibicuí, Cerro do Tigre (B).

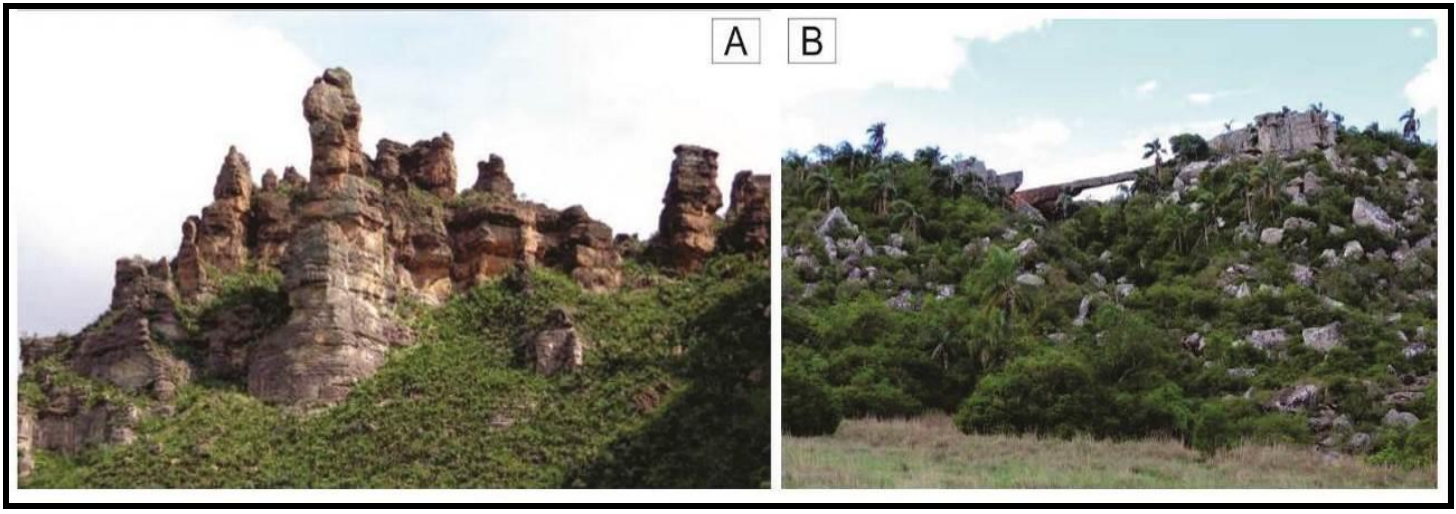

Fonte: Autores, (A 2011) e (B 2016)

Localização: (A) Latitude Sul $10^{\circ} 51^{\prime}$ e Longitude Oeste $46^{\circ} 49^{\prime}$ (B) Latitude Sul $29^{\circ} 40^{\prime}$ e Longitude Oeste $55^{\circ} 24^{\prime}$

As feições Piramidais são formadas pela desagregação de rochas areníticas favorecidas pelas estruturas rúpteis subverticais. São feições que apresentam um topo pontiagudo pela resistência parcial da rocha cimentada e, um significativo depósito de talús e colúvios na sua volta, formado por fragmentos de rochas e blocos oriundos das porções superiores das próprias feições.

$\mathrm{Na}$ bacia hidrográfica do rio Novo, esse tipo de forma pode ser observada junto a Serra da Muriçoca, localizada na porção noroeste da área (Figura 9A). Na bacia hidrográfica do rio Ibicuí, esse tipo de forma encontra-se junto à margem direita do rio Ibicuí, próximo ao rio Jaguarí, representado pelo Cerro Pontudo (Figura 9B).

Figura 9: Morros areníticos em forma de Pirâmide, na bacia hidrográfica do rio Novo (A) e na bacia hidrográfica do rio Ibicuí são vistos na margem esquerda do rio Jaguari, tributário do rio lbicuí (B).

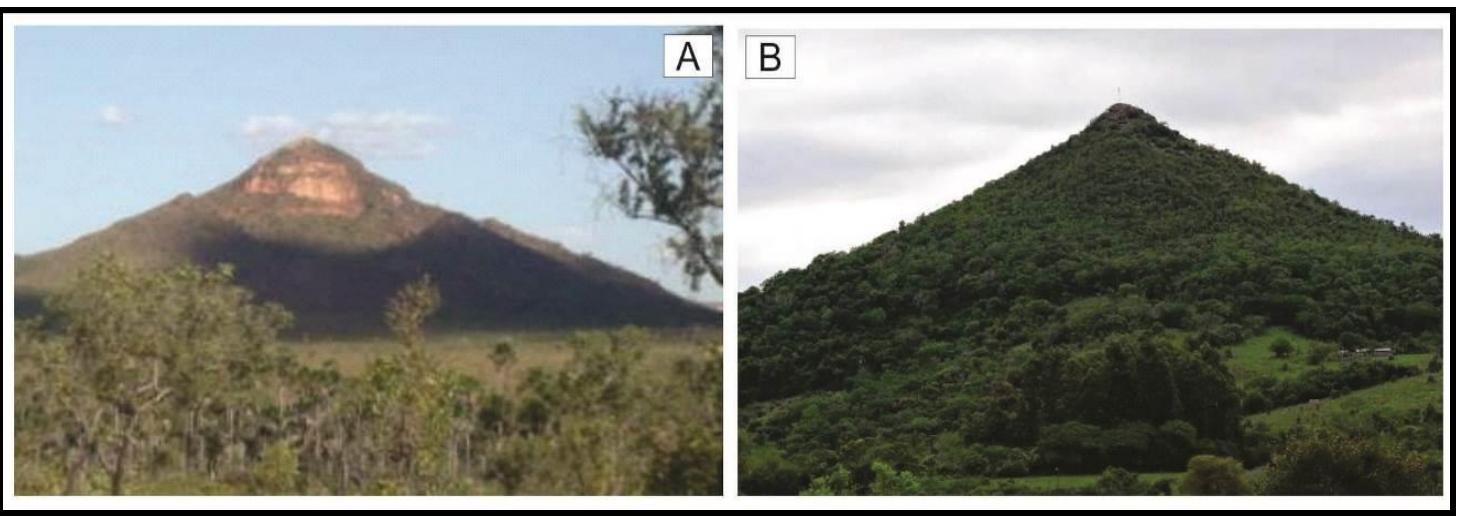

Fonte: Autores, (A 2011) e (B 2016)

Localização: (A) Latitude Sul $10^{\circ} 38^{\prime}$ e Longitude Oeste $46^{\circ}$ e $57^{\prime}$ (B) Latitude Sul $29^{\circ} 43^{\prime}$ e Longitude Oeste $54^{0} 54^{\prime}$

A formação de Furnas e Cavernas ocorre devido à ação mecânica e de dissolução dos cimentos, pela ação das águas superficiais e subterrâneas.

A formação de arcos ocorre por um conjunto de juntas intercruzadas que, pela ação do intemperismo e da erosão, provocam a queda de blocos favorecendo aberturas de furnas ou perfurações na feição rochosa.

$\begin{array}{llllll}\text { Caminhos de Geografia } & \text { Uberlândia - MG } & \text { v. 19, n. } 67 & \text { Set/2018 } & \text { p. 143-156 Página } 150\end{array}$


O fluxo subterrâneo, controlado por lineamentos estruturais e estratificação da rocha arenítica com irregularidades de cimentação e resistência entre as camadas gera amplas formas de dutos e grutas.

$\mathrm{Na}$ bacia hidrográfica do rio Novo, um exemplo destas feições é a "Pedra Furada" (Figura 10A) onde o avanço dos processos erosivos, ampliam os espaços internos da feição, que evoluem para perfurações formando arcos. Na bacia hidrográfica do rio lbicuí, a formação de grutas e furnas, se deve a evolução e aceleração de erosão associada ao fluxo subterrâneo, como é o caso da Gruta Nossa Senhora de Fátima, em Nova Esperança do Sul (Figura 10B).

Figura 10: Furnas e Cavernas da bacia hidrográfica do rio Novo, Pedra Furada (A) e da bacia hidrográfica do rio Ibicuí, Gruta Nossa Senhora de Fátima (B).

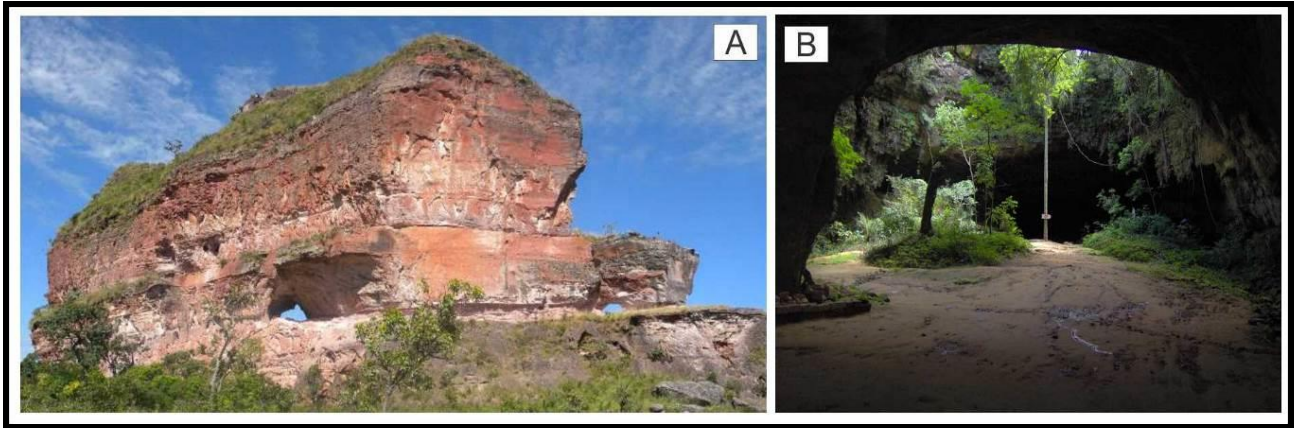

Fonte: Autores, (A 2011) e (B 2006)

Localização: (A) Latitude Sul $10^{\circ} 52^{\prime}$ e Longitude Oeste $47^{\circ} 23^{\prime}$ (B) Latitude Sul $29^{\circ} 26^{\prime}$ e Longitude Oeste $54^{\circ} 49^{\prime}$

A formação de Pináculos ocorre por desagregação da rocha arenítica, favorecido por dissolução diferencial seguindo estruturas sedimentares e fraturamentos subverticais predominantes, que geram nas porções finais, elevações aciculares.

$\mathrm{Na}$ bacia hidrográfica do rio Novo, o Pico da Panela (Figura 11A), conhecido localmente por Pico da Sovela, é um morrote em forma de Pináculo que está relacionado ao recuo erosivo da escarpa da Serra Geral. Já na bacia hidrográfica do rio lbicuí, estas feições estão associadas a morros e morrotes desagregados, que perdem sua forma tabular e piramidal, restando elevações rochosas na forma de torres e pináculos (Figura 11B).

Figura 11: Formações de Pináculos na bacia hidrográfica do rio Novo, Morro da Sovela $(A)$ e na bacia hidrográfica do rio Ibicuí (B).

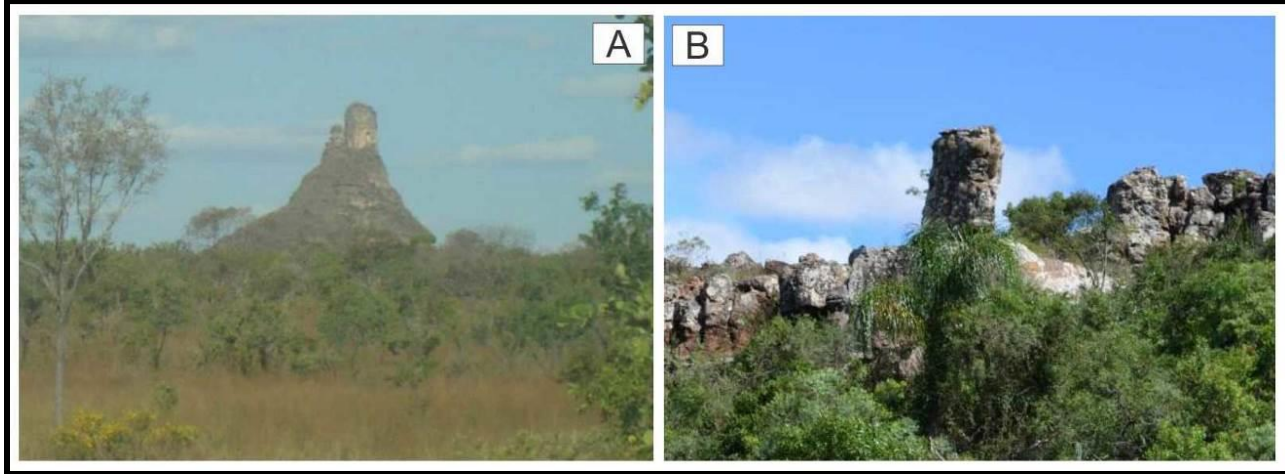

Fonte: Autores, (A 2011) e (B 2006)

Localização: (A) Latitude Sul $11^{\circ} 05^{\prime}$ e Longitude Oeste $46^{\circ} 38^{\prime}$ (B) Latitude Sul $29^{\circ} 02^{\prime}$ e Longitude Oeste $54^{\circ} 23^{\prime}$ 


\section{FORMAS E FEIÇÕES LOCAIS}

As Feições em Blocos e Matacões estão em rochas desagregadas que assumem diferentes aspectos originando diferentes ornamentações, esculturas e entalhes. Estas são formadas por resquícios rochosos oriundos de estratificação de arenitos originados por processos de erosão diferencial, em que os agentes do intemperismo agem, com maior ou menor intensidade, de acordo com o diferenciado grau de resistência das camadas rochosas existentes.

A Pedra da Baliza (Figura 12A), na bacia hidrográfica do rio Novo, é formada por um empilhamento de três camadas de rochas areníticas com estratificações cruzadas de baixo ângulo, onde as altas colunas de rochas apresentam uma seção basal gerada pelo progressivo aprofundamento da erosão que age ao se redor. Na feição, ocorrem intercalações de arenitos com diferentes texturas e variação na concentração de ligantes, óxido de ferro e sílica, que servem de cimentos e são responsáveis pela resistência e forma da mesma.

$\mathrm{Na}$ bacia hidrográfica do rio lbicuí, formas semelhantes são geradas em arenitos controlados pela estratificação das camadas e fraturas presentes nas mesmas. A Figura 12B, apresenta uma feição deste tipo, localizada na margem direita do rio lbicuí, porção norte da bacia hidrográfica em questão.

Figura 12: Feição em Blocos e Matacão da bacia hidrográfica do rio Novo, Pedra da Baliza (A) e blocos de arenitos na bacia hidrográfica do rio Ibicuí (B).

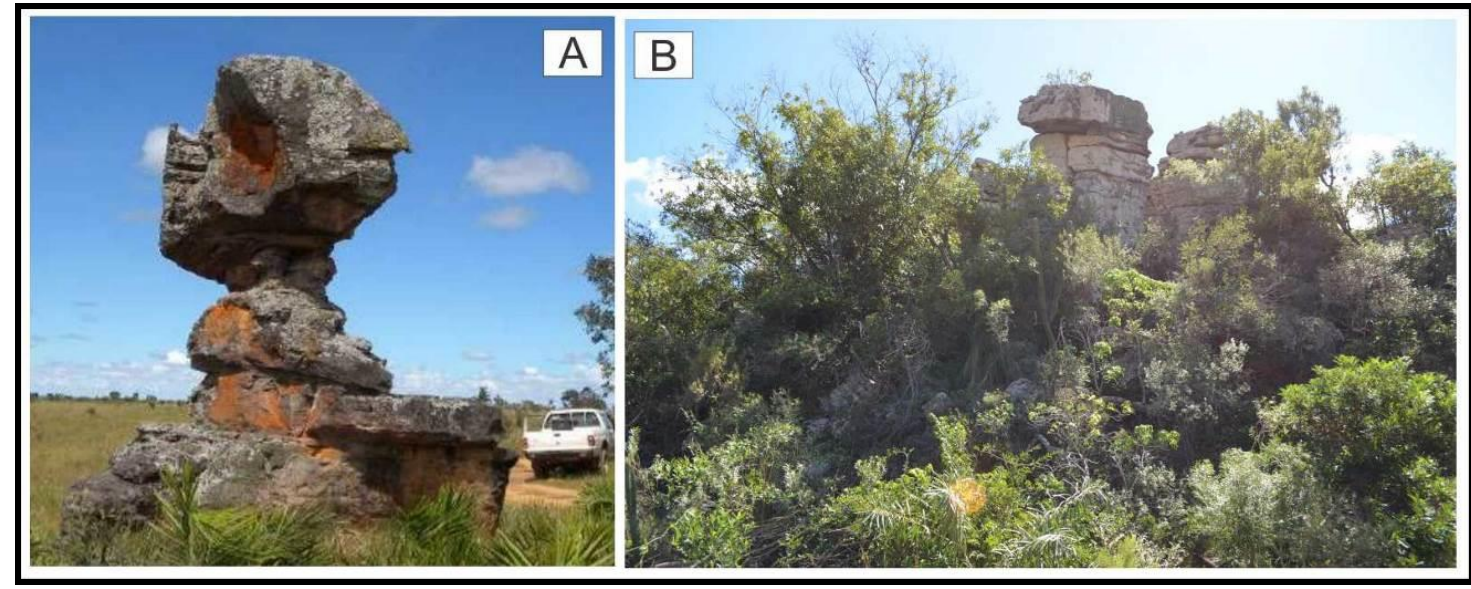

Fonte: Autores, (A 2011) e (B 2014)

Localização: (A) Latitude Sul 10 $37^{\prime}$ e Longitude Oeste $46^{\circ} 06^{\prime}$ (B) Latitude Sul $29^{\circ} 02^{\prime}$ e Longitude Oeste $54^{\circ} 23^{\prime}$

As Feições de Blocos Areníticos com Coberturas Imbricadas são formadas por grandes blocos de rochas areníticas, que se sobressaem no relevo, apresentando uma cobertura ou capa externa com "forma imbricada", ou seja, semelhante a "escamas de peixes". Esta feição tem uma estrutura original decorrente de marcas de correntes de fluxo, sobre o substrato areno-argiloso que é preservado, o qual posteriormente foi retrabalhado por processos de intemperismo e erosão que incidem sobre a mesma, dando forma atual a feição.

Segundo Larousse (2004 citado por Moreira, 2008) imbricado significa que as partes de um agregado se sobrepõem parcialmente umas às outras, como as telhas de um telhado ou as escamas de um peixe.

No alto curso da bacia hidrográfica do Rio Novo, pode-se observar estas feições representadas por significativos blocos areníticos com coberturas imbricadas, relacionando-se ao recuo da Serra da Muriçoca, na porção noroeste da área (Figura 13A). Na bacia hidrográfica do rio Ibicuí ocorrem em alguns blocos de rochas areníticas localizadas na porção norte da bacia (Figura 13B). 
Figura 13: Blocos areníticos com coberturas imbricadas na bacia hidrográfica do rio Novo $(A)$ e na bacia hidrográfica do rio Ibicuí (B).

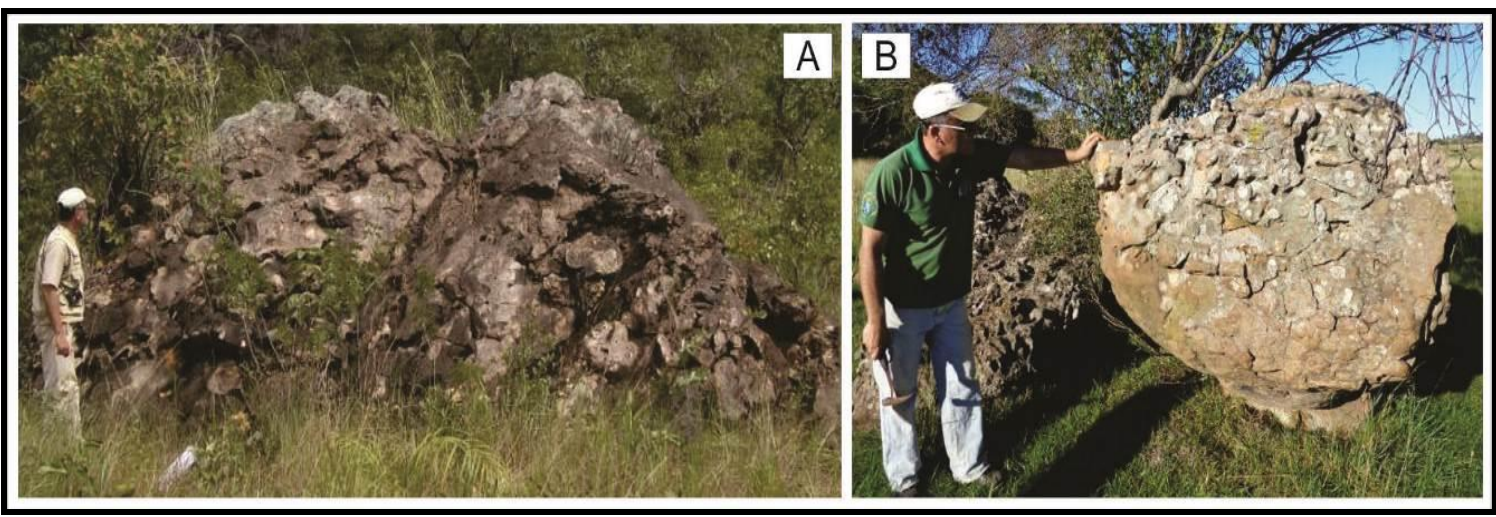

Fonte: Autores, (A 2011) e (B 2014)

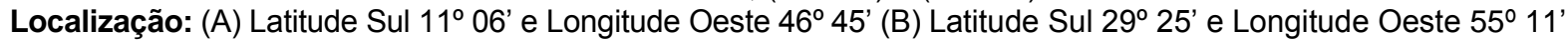

\section{FORMAS E FEIÇÕES DE EROSÃO E DEPOSIÇÃO DE AREIAS}

Outra feição importante em áreas areníticas é o desenvolvimento de voçorocas. Sua origem está associada aos processos erosivos que se iniciam em áreas de encostas, devido a canais de escoamento superficiais e subterrâneos, controlados por lineamentos e condicionados a baixa aglutinação entre os grãos de rochas areníticas com pouca cimentação.

$\mathrm{Na}$ bacia hidrográfica do rio Novo, as voçorocas encontram-se principalmente nas encostas arenosas e escarpadas da Serra da Muriçoca e da Serra Geral (Figura 14A) e, em colinas arenosas condicionadas por rodovias locais com traçados acompanhando a inclinação do terreno.

$\mathrm{Na}$ bacia hidrográfica do rio lbicuí, estas feições ocorrem associadas à morrotes e cornijas de arenito e na meia encosta de colinas. Voçorocas de grande extensão e profundidade (Figura 14B) são encontradas no município de Cacequi.

Figura 14: Voçoroca da borda da Serra Geral, na bacia hidrográfica do rio Novo $(A)$ e voçoroca do Areal da bacia hidrográfica do rio Ibicuí, junto ao rio Areal (B).

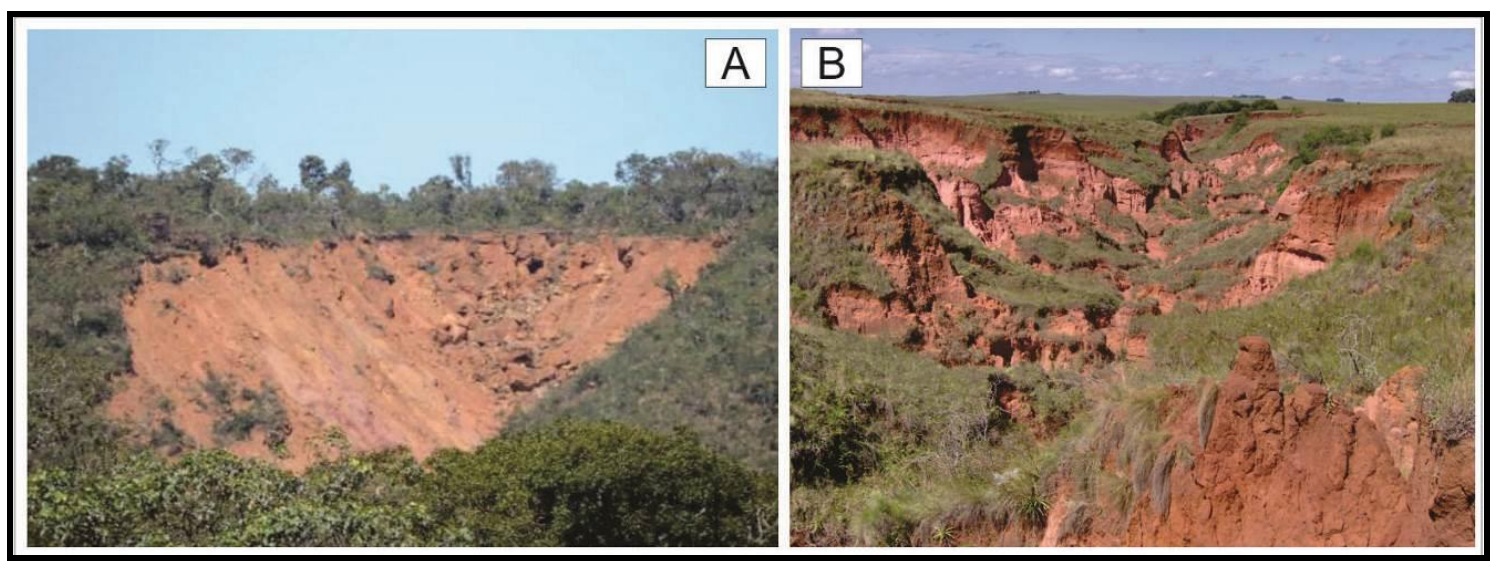

Fonte: Autores, (A 2011) e (B 2014)

Localização: (A) Latitude Sul $10^{\circ} 50^{\prime}$ e Longitude Oeste $46^{\circ} 08^{\prime}$ (B) Latitude Sul $29^{\circ} 54^{\prime}$ e Longitude Oeste $54^{\circ} 45^{\prime}$

As formas de deposição são características do ambiente com rochas sedimentares areníticas com forte ação de desagregação. Feições Eólicas se caracterizam por uma extensa deposição de sedimentos arenosos que iniciam sua acumulação pela ação das águas e são retrabalhados pelo

$\begin{array}{llllll}\text { Caminhos de Geografia } & \text { Uberlândia - MG } & \text { v. 19, n. } 67 & \text { Set/2018 } & \text { p. 143-156 Página } 153\end{array}$


vento. Basicamente estão associadas a intensos processos erosivos e a fragilidade das rochas arenosas locais, que servem de área fonte dos sedimentos que formam as feições.

$\mathrm{Na}$ bacia hidrográfica do rio Novo, destacam-se as Dunas do Jalapão (Figura 15A) que se caracterizam por um depósito de areia com cerca de $16 \mathrm{~m}$ de altura e tem como fonte de sedimentos a base da encosta da Serra do Espírito Santo. Local este, onde inicia o processo de deposição em uma faixa estreita, seguindo o curso do Riacho da Areia, abrindo em forma de "Leque Fluvial", até expandir-se lateralmente junto a sua foz, local onde ocorre o retrabalhamento dos sedimentos pelo vento, dando forma e característica de duna.

$\mathrm{Na}$ bacia hidrográfica do rio Ibicuí, as deposições ocorrem associadas aos areais (Figura 15B) que se originam pela desagregação de rochas pelo efeito pluvial e posterior retrabalhamento do vento gerando dunas.

Figura 15: Formas de deposição na bacia hidrográfica do rio Novo, as Dunas do Jalapão $(A)$ e na bacia hidrográfica do rio lbicuí, o Areal do Puitã (B).

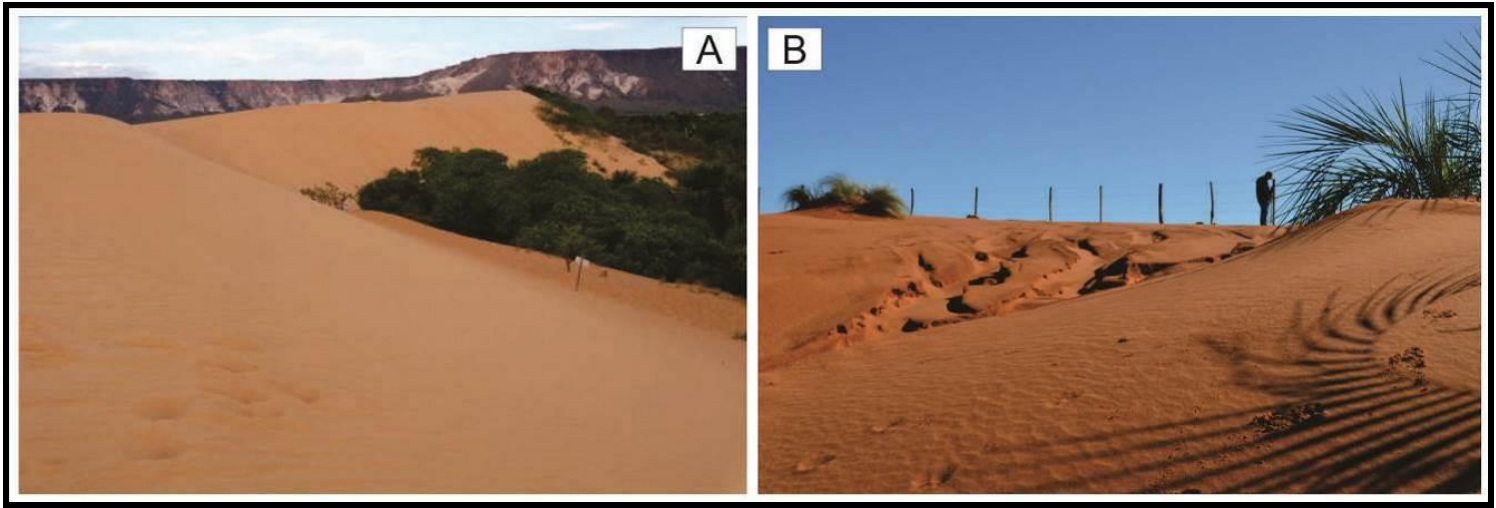

Fonte: Autores, (A 2011) e (B 2014)

Localização: (A) Latitude Sul $10^{\circ} 33^{\prime}$ e Longitude Oeste $46^{\circ} 38^{\prime}$ (B) Latitude Sul $29^{\circ} 29^{\prime}$ e Longitude Oeste $55^{\circ} 27^{\prime}$

\section{CONSIDERAÇÕES FINAIS}

De modo geral, os aspectos geológicos-geomorfológicos em ambas as bacias hidrográficas estudadas, estão relacionados aos depósitos sedimentares e rochas areníticas que se assemelham, nos processos superficiais atuantes e nas formas geradas.

Os fatores responsáveis pela evolução das feições erosivas dos arenitos são de múltipla natureza, relacionados a atributos das rochas sedimentares, como textura, estrutura sedimentar e cimentação e/ou relacionados a estruturas rúpteis como a presença de falhas e fraturas nas mesmas, possibilitando a circulação da água no interior dos maciços rochosos, viabilizando uma progressiva ação do intemperismo e erosão desde a superfície até grandes profundidades, bem como a formação de uma malha composta por material friável.

A pesquisa permite, a partir da descrição das formas e feições em rochas areníticas, compreender melhor a expressiva geodiversidade encontrada nas bacias hidrográficas do Rio Novo, estado do Tocantins e na bacia hidrográfica do Rio Ibicuí, estado do Rio Grande do Sul.

Ainda, os arenitos são importantes na formação das diferentes formas do relevo e nos processos da dinâmica natural com o desenvolvimento de formas de relevo que podem caracterizar a paisagem sobre estas rochas, semelhantes ao que acontece com as rochas carbonáticas.

Deste modo, estudos sobre a possibilidade da dissolução química ter atuado nas rochas areníticas são importantes para que, associado com a presença de dutos e da hidrologia, possa ser identificado um possível carste, associado aos arenitos. 


\section{AGRADECIMENTOS}

A Coordenação de Aperfeiçoamento de Pessoal de Nível Superior (CAPES) pela Concessão de bolsa, a qual foi imprescindível para realização do pós-doutorado, que resultou no presente artigo. Ao curso de Geografia, Campus de Porto Nacional da Universidade Federal do Tocantins (UFT) pela liberação para realização do pós-doutorado, que resultou no presente artigo. Ao Instituto Chico Mendes de Conservação da Biodiversidade (ICMBio) pela concessão de licença de pesquisa e apoio nos trabalhos de campo.

\section{REFERÊNCIAS}

AB'SABER, A. N. Topografia Ruiniformes no Brasil. São Paulo - SP: Geomorfologia, no 50, 1977.

CHABERT, C.; COURBON, P. Atlas des Cavités non Calcaires du Monde. Union Internationale de Spéléologie, 1997.

CRISTO, S. S. V. de. Abordagem Geográfica e Análise do Patrimônio Geomorfológico em Unidades de Conservação da Natureza: Aplicação na Estação Ecológica Serra Geral do Tocantins e Área de Entorno - Estados do Tocantins e Bahia. Porto Alegre - RS: Universidade Federal do Rio Grande do Sul (UFRGS), Instituto de Geociências, Programa de Pós-Graduação em Geografia (POSGEA), Tese de doutorado, 2013. 245p.

CRISTO, S. S. V. DE.; ROBAINA, L. E. DE S. Análise geomorfológica em Unidades de Conservação da Natureza: Estação Ecológica Serra Geral do Tocantins - Estados do Tocantins e da Bahia. Goiânia - GO: Ateliê Geográfico, v. 10, n. 3, 2016. p. 73-88 Disponível em: https://www.revistas.ufg.br/atelie/article/view/31162/22514 Acesso em: 21 de março de 2017

GASPAR, M. T. P. Sistema Aqüífero Urucuia: caracterização regional e propostas de gestão. Brasília - DF: Tese de Doutorado, Universidade Federal de Brasília, Instituto de Geociências, 2006.

GUERRA, A. J. T. Dicionário Geológico Geomorfológico. Rio de Janeiro - RJ: 1ª ed., IBGE, 1993. $446 p$

HARDT, R.; PINTO, S. dos A. F. Carste em litologias não carbonáticas. Revista Brasileira de Geomorfologia, v. 10, № 2, 2009. p. 99 - 105 Disponível em:www.bibliotecadigital.gpme.org.br/bd/wp-content/uploads/bd-gpme-0519.pdf. Acesso em 23 de março de 2017.

MEIRA, S. A.; SANTOS, G. B. dos. Inventário e quantificação da potencialidade educativa do patrimônio geológico da Serra dos Tapuias, Riachão das Neves (BA). Uberlândia - MG: CAMINHOS DE GEOGRAFIA - revista online, v. 17, $n^{\circ} .58,2016$. p. $34-52$ Disponível em: http://www.seer.ufu.br/index.php/caminhosdegeografia. Acesso em: 23 de março de 2017

MELO, M. S. DE.; GUIMARÃES, G. B.; PONTES, H. S.; MASSUQUETO, L. L.; PIGURIM, I,; BAGATIM, H. Q.; GIANNINI, P. C. F. Carste em rochas não-carbonáticas: o exemplo dos arenitos da formação Furnas, Campos Gerais do Paraná/Brasil e as implicações para a região. Campinas - SP: SBE, Espeleo - Tema, v.22, n.1, 2011.

MORAIS, F.; ROCHA, S da. Cavernas em arenito no planalto residual do Tocantins. Campinas - SP: SBE, Espeleo - Tema, v.22, n.1. 2011. Disponível em: www.cavernas.org.br/espeleo-tema.asp. Acesso em: 23 de março de 2017.

MOREIRA, J. C. Patrimônio geológico em Unidades de Conservação: atividades interpretativas, educativas e geoturísticas. Florianópolis - SC: UFSC, Programa de Pós-graduação em Geografia, Tese (Doutorado em Geografia), 2008.

ROBAINA, L. E. de S. e BAZZAN, T. Feições cársticas em rochas siliciclásticas no oeste do Estado do Rio Grande do Sul - Brasil. Revista Brasileira de Geomorfologia, ano 9, ㄲo 2, 2008. Disponível em: http://www.ugb.org.br/final/normal/artigos/RBG_9.2/Art\%2005\%20-\%20Feicoes\%20-\%209n2.pdf. Acessom em: 21 de março de 2017

ROBAINA, L. E. de S.; TRENTIN. R.; LAURENT. F.; SCCOTI, A. A. V. Zoneamento em unidades morfolitológicas da bacia do rio lbicuí e sua relação com processos superficiais e o uso do solo. Revista Brasileira de Geomorfologia, vol.16, $\mathrm{n}^{\circ}$ 1, 2015. p. 63-77 
ROBAINA, L. E. S.; TRENTIN, R.; BAZZAN, T.; RECKZIEGEL, E. W.; VERDUM, R.; DE NARDIN, D. Compartimentação geomorfológica da bacia hidrográfica do lbicuí, Rio Grande do Sul, Brasil: proposta de classificação. Revista Brasileira de Geomorfologia, v.11, n.2, 2010. p.11-23. https://doi.org/10.20502/rbg.v11i2.148

SUERTEGARAY, D. M. A.; ROSSATO, M. R.; BELLANCA, E. T.; FACHINELLO, A.; CÂNDIDO, L. A.; DA SILVA, C. R. (org.). Terra feições ilustradas. Porto Alegre - RS: UFRGS, 2003. 263p

TRENTIN, R.; SANTOS, L. J. C.; ROBAINA, L. E. S. Compartimentação Geomorfológica da Bacia Hidrográfica do Rio Itu, Oeste do Rio Grande do Sul - Brasil. Uberlândia - MG: Sociedade \&natureza (UFU. Online), v. 24, 2012. p. 127-142

Recebido em: 01/09/2017

Aceito para publicação em: 26/09/2018 